\title{
Validation of the New Algorithm for Rain Rate Retrieval from AMSR2 Data Using TMI Rain Rate Product
}

\author{
Elizaveta Zabolotskikh ${ }^{1}$ and Bertrand Chapron ${ }^{1,2}$ \\ ${ }^{1}$ Satellite Oceanography Laboratory, Russian State Hydrometeorological University, Malookhtinsky 98, St. Petersburg 195196, Russia \\ ${ }^{2}$ Ifremer, Centre de Brest BP70, 29280 Plouzane, France \\ Correspondence should be addressed to Elizaveta Zabolotskikh; liza@rshu.ru
}

Received 26 June 2014; Revised 15 August 2014; Accepted 1 October 2014

Academic Editor: Sahra Kacimi

Copyright (c) 2015 E. Zabolotskikh and B. Chapron. This is an open access article distributed under the Creative Commons Attribution License, which permits unrestricted use, distribution, and reproduction in any medium, provided the original work is properly cited.

\begin{abstract}
A new algorithm is derived for rain rate (RR) estimation from Advanced Microwave Sounding Radiometer 2 (AMSR2) measurements taken at 6.9,7.3, and $10.65 \mathrm{GHz}$. The algorithm is based on the numerical simulation of brightness temperatures $\left(T_{B}\right)$ for AMSR2 lower frequency channels, using a simplified radiation transfer model. Simultaneous meteorological and hydrological observations, supplemented with modeled values of cloud liquid water content and rain rate values, are used for the calculation of an ensemble of AMSR2 $T_{B}$ s and RRs. Ice clouds are not taken into account. AMSR2 brightness temperature differences at Cand X-band channels are then used as inputs to train a neural network (NN) function for RR retrieval. Validation is performed against Tropical Rain Measurement Mission (TRMM) Microwave Instrument (TMI) RR products. For colocated AMSR2-TMI measurements, obtained within $10 \mathrm{~min}$ intervals, errors are about $1 \mathrm{~mm} / \mathrm{h}$. The new algorithm is applicable for RR estimation up to $20 \mathrm{~mm} / \mathrm{h}$. For RR $<2 \mathrm{~mm} / \mathrm{h}$ the retrieval error is $0.3 \mathrm{~mm} / \mathrm{h}$. For RR $>10 \mathrm{~mm} / \mathrm{h}$ the algorithm significantly underestimates TMI RR.
\end{abstract}

\section{Introduction}

Rain gauges and meteorological radars still remain to be the most precise tools for precipitation measurements, but their coverage is obviously insufficient for climate studies and to understand changes in the global hydrological cycle [1]. In turn, satellite instruments are the most appropriate means to measure precipitation over the ocean where in situ data are scarce. Effective in terms of global and regular coverage, satellite measurements typically provide precipitation estimates at low spatial resolution with often questionable accuracy. Over land, estimates are based on ice scattering at high microwave frequencies, whereas over oceans microwave emission of hydrometeors at lower frequencies is mostly used $[2,3]$. Some studies describe the use of infrared (IR) sensors to estimate precipitation [4, 5]. Most are based on statistical methods, using regression between passive microwave estimates and coincident IR pixel data. Geostationary satellites can provide this high temporal and relatively high spatial resolution but are reported to be inaccurate in warm rains [6]. Moreover, IR data are limited to cloud-top information, and precise rain rate (RR) estimation from these data is not feasible. Nowadays, the most direct precipitation measurements from space are provided by precipitation radars. Since 1997 Precipitation Radar (PR) aboard the Tropical Rainfall Measuring Mission (TRMM) performed advanced retrievals of RRs over tropics [7]. Since 2006 the Cloud Profiling Radar (CPR) aboard CloudSat satellite expanded radar capabilities to sense very light rains [8]. Further progresses in precipitation measurement science are associated with combined precipitation products, making use of different sensors [6,9-12], with the analysis of inherent instrument errors [13]. At last, the launch of the new Global Precipitation Mission (GPM) in February 2014, similar to TRMM in combining passive microwave instrument, GPM Microwave Imager (GMI), and microwave radar, Dual-Frequency Precipitation Radar (DPR), but with an extended $\left(\sim \pm 65^{\circ}\right)$ latitude coverage, opens new possibilities for calibration and combined use of active and passive microwave instruments for advanced precipitation 
studies [14]. GPM global observations will expand the data records started with previous precipitation missions and improve precipitation estimates around the globe.

In spite of low spatial resolution and limitations compared with precipitation radars, satellite passive microwave measurements remain valuable regular source of global information on precipitation. Ability to infer accurate precipitation estimates from these measurements has been repeatedly proven in numerous studies [1,2,15-17]. High quality precipitation measurements by polar orbiting passive microwave instruments started with the launch of the first Special Sensor Microwave Imager (SSM/I) in 1987. Since then, many efforts have been undertaken for the development of algorithms for precipitation parameter retrievals. Most of the studies relate to RR retrievals over the oceans. High land emission and its great inhomogeneity complicate RR retrievals over the land [3]. Though, recent studies devoted to the estimation of land emissivities without a need for ancillary data [18] can help to improve these retrievals. Satellite passive microwave sensors allowing emission-based RR retrievals over the ocean include SSM/I and Special Sensor Microwave Imager and Sounder (SSMIS), TRMM Microwave Instrument (TMI), Advanced Microwave Scanning Radiometer-Earth (AMSR-E) Observing System and its successor AMSR2, and Polarimetric Radiometer WindSat. A number of methods to derive different precipitation parameters (rain rate, precipitation vertical structure) from these instruments have been developed $[3,15$, 19-22], including the Goddard Profiling algorithm (GPROF) [23], the Unified Microwave Ocean Retrieval Algorithm (UMORA) [17, 24], and the NOAA/NESDIS algorithm [25]. The longest-available passive microwave rain rate product, produced operationally by Remote Sensing Systems (RSS) based on SSM/I (SSMIS) data, is derived using an ocean-only $\mathrm{RR}$ retrieval with UMORA algorithm. Large efforts have been made by RSS for satellite intercalibration to cover almost 3 decades, and discontinuities in the product are minimized [26].

Most of the listed rain retrieval algorithms are physically based, exploring the sensitivity of microwave brightness temperatures to the changes in cloud and rain microphysical properties [27-29]. Little, if any, study, related to rain, concerned C- or X-band. These bands are typically used for the ocean parameter retrievals as the atmosphere is almost transparent for the radiation at such microwave frequencies, even under heavy clouds and light rains (up to $2 \mathrm{~mm} / \mathrm{h}$ ) [30]. At the rain rate of $2 \mathrm{~mm} / \mathrm{h}$, the optical depth of the atmosphere, with the total atmospheric water vapor content of $26 \mathrm{~kg} / \mathrm{m}^{2}$, total liquid water content of $0.26 \mathrm{~kg} / \mathrm{m}^{2}$, and rain layer thickness of $1.35 \mathrm{~km}$, is about $\sim 0.025$ at $6.9 \mathrm{GHz}$ and $\sim 0.027$ at $10.65 \mathrm{GHz}$.

Microwave brightness temperature simulation further shows that the brightness temperature $\left(T_{B}\right)$ increases towards a maximum and then drops off as rainfall rates increase further [31]. Figure 1 shows the results of the numerical calculations of $T_{B}$ of the atmosphere-ocean system with fixed hydrological and meteorological parameters for horizontally polarized AMSR2 channels at 6.9 and $10.65 \mathrm{GHz}$ for different values of rain rates. These calculations have been

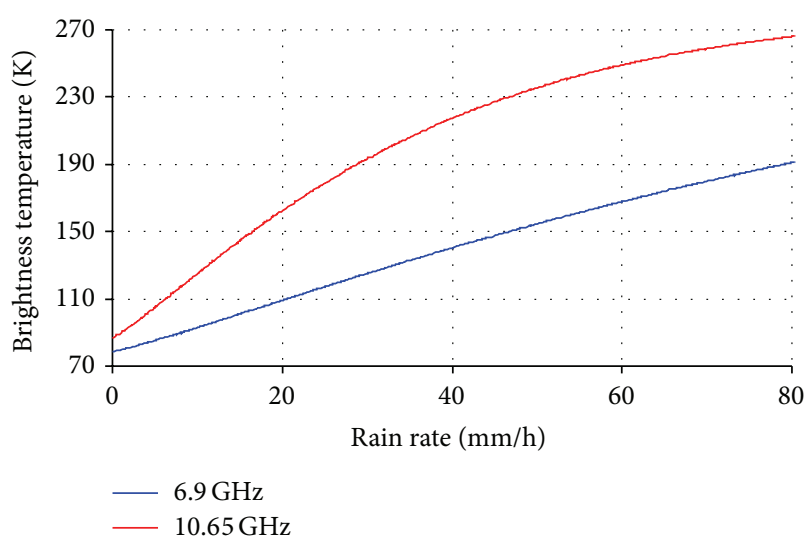

FIGURE 1: Simulated horizontally polarized brightness temperature as a function of rain rate for $6.9 \mathrm{GHz}$ (upper curve) and for $10.65 \mathrm{GHz}$ (lower curve). All the other meteorological and hydrological parameters are fixed. Total atmospheric water vapor content is $26 \mathrm{~kg} / \mathrm{m}^{2}$, total cloud liquid water content is $0.26 \mathrm{~kg} / \mathrm{m}^{2}$, rain layer thickness is $1.35 \mathrm{~km}$, sea surface wind speed is $5 \mathrm{~m} / \mathrm{s}$, and sea surface temperature is $10^{\circ} \mathrm{C}$.

performed with limitations discussed later. For rain retrieval methods, the most important difference between microwave radiometer channel frequencies is the range of the rain rates for which $T_{B}$ increases (emission range) and the range for which $T_{B}$ decreases (scattering range). $T_{B}$ at low frequencies including $\mathrm{C}$ - and X-bands tends to increase over most of the rainfall range, thus enabling the use of emission-only type schemes. $T_{B}$ at higher frequencies saturates quickly and then decreases for most of the rainfall range [31]. The higher the channel frequency, the more important the vertical structure of precipitation in $T_{B}$ modeling, in particular the height of the freezing level and the hydrometeor size and form distributions along the height [32]. Therefore, RR retrievals at higher frequencies need a priori knowledge of hydrometeor profile. Separation between atmospheric scattering and emission presents another problem which is solved in some studies using polarization sensitivity of measurements [17, 21]. But in the case of strongly polarized signals from the ocean surface, hard to be theoretically modeled [33], especially for high winds, the radiative transfer equation simplifications discussed in these studies can lead to errors.

$\mathrm{C}$ - and X-band $T_{B}$ measurements are far from RR saturation range and thus attractive for RR algorithm development.

In May 2012, the new Japan passive microwave radiometer AMSR2 was launched on GCOM-W1 satellite. Starting from August 2012 calibrated Level 1B brightness temperatures are available for the scientific community. This unique instrument replaced the similar AMSR-E on Aqua satellite which stopped its performance in October 2011 after about 9 years of successful functioning. The new AMSR2 has not only improved calibration and spatial resolution compared with its predecessor but also includes two new channels working in C-band [34]. These channels are specifically intended for the detection of pixels contaminated by radio frequency interference (RFI). In this study, the measurements at these 
additional channels in C-band are suggested to be used for rain rate estimation, exploring similar dependence of $T_{B}$ at $\mathrm{C}$ - and X-band frequencies on such oceanic parameters as sea surface temperature and sea surface wind speed. The algorithm for RR retrievals from AMSR2 C- and X-band channel measurements is based on the physical modeling of brightness temperatures over the oceans with their following inversion using neural networks (NNs). The validation of the algorithm for AMSR2 Level 1B data is done against TRMM rain rate product based on TMI measurements provided by RSS.

Numerical simulation of the brightness temperatures of the ocean-atmosphere system is done using the parameterization of [35] to calculate the atmospheric attenuation due to liquid water. The attenuation of rain is parameterized by Liebe and Layton in [35] using Mie formulas. Simplification of the radiation transfer equation is done using the attenuation coefficient instead of the absorption one. Such a simplification allows accounting for the negative effect of scattering but underestimates its positive effect due to scattering forward [36]. One of the essential simplifications of the current study is to dismiss ice particles in the model. Ice water interacts with microwave radiation essentially via scattering process [37]. Though low frequency passive microwave measurements are insensitive to some ice clouds [38], heavy rains are often associated with strong convection and large ice particles in clouds and precipitation in the form of hail and graupel. The size of such frozen water particles easily reaches the values comparable with the wavelengths of low frequency AMSR2 channels.

Computer simulations of the brightness temperatures are carried out for the dataset of meteorological and hydrological data measurements, complemented by modeled liquid water content and rain parameter data. The dataset, used for $T_{B}$ calculations, is described in detail in Section 2. The geophysical model, establishing the relationship between the total brightness temperature and the atmospheric and oceanic parameters, is described in Section 3.1. After $T_{B}$ calculation, NNs inversion algorithm has been trained on the ensemble of simulated $T_{B}$ values and rain rates. Four differences in AMSR2 measurements at six lower frequency channels in C- and X-bands have been used as NNs inputs, and only one parameter, RR, as an NNs output. At $10.65 \mathrm{GHz} T_{B}$ is far from saturation even for tropical atmospheres with high values of atmospheric water vapor content, cloud liquid water content, and rain layer thickness up to $20 \mathrm{~mm} / \mathrm{h}$ rain rates (RR). So we limited the data by the maximum $R R$ value of $20 \mathrm{~mm} / \mathrm{h}$. NNs configuration is described in Section 3.2. After having been trained, the algorithm has been applied to actual AMSR2 measurements for the period of 20122013 and validated against the Tropical Rain Measurement Mission (TRMM) Microwave Instrument (TMI) rain rate product downloaded from the Remote Sensing System Data Center. The validation procedure is described in Section 4. The algorithm performance relative to TMI RR product was also compared with the consistency of AMSR2-TMI RSS RR products. The validation results are discussed in Section 5, followed with conclusions in Section 6.

\section{Data for Numerical Simulation}

Radiosonde ( $\mathrm{r} / \mathrm{s}$ ), meteorological, wind speed, forms, and amount of clouds (percentage of cloud cover), and hydrophysical (seasurface temperature and salinity) simultaneous measurements were used for brightness temperature calculations. High latitude part of this dataset was used, for example, in [39] for the development of the regional Arctic algorithms for total atmospheric water vapor content $(\mathrm{Q})$ and total cloud liquid water content $(\mathrm{W})$ retrievals from SSM/I and AMSR-E data. The dataset was significantly extended by addition of measurements in tropics and subtropics. The measurements were taken by the research vessels of the Far Eastern Research Hydrometeorological Institute (USSR/Russia) during the period of 1966-1993. The dataset included about 3000 radiosondes with simultaneous seasurface temperature and salinity measurements. Wind speed data, as they are not correlated with the other geophysical parameters, were added artificially, randomly varying from 0 up to $50 \mathrm{~m} / \mathrm{s}$.

$\mathrm{R} / \mathrm{s}$ profiles of air temperature, humidity, and pressure were complimented by cloud liquid water content $(\omega)$ profiles, modeled in accordance with [40]. Forms and amount of clouds were determined by experienced meteorologists during the radiosonde launch. Relative humidity is the variable which governs the physical processes in the atmosphere relating to different phases of water. Upper and lower boundaries of cloudiness were estimated using relative humidity and temperature profiles. Uniform liquid water content profiles were taken for the clouds with thickness less than $1 \mathrm{~km}$ with typical liquid water content values of $0.05-$ $0.10 \mathrm{~g} / \mathrm{m}^{3}$. For clouds with thickness greater than $1 \mathrm{~km}, \omega$ profiles were described by triangle function. In this case $\omega$ maximum was located at the one-third of thickness below the upper boundary of cloudiness. This maximum increases with the increase of the cloud thickness. A linear relation was assumed between $\omega$ and the cloud amount. The decrease of liquid water content values with the decrease of cloud temperature for the observed form of clouds was also taken into account, based on the statistical data, describing liquid water content distribution in the clouds of different forms and temperatures. Precipitation originates as a statistical event within the clouds suspended in saturated air [35]. Its vertical distribution is separated into two regions by the height of the $0^{\circ} \mathrm{C}$ isotherm which can vary between $6 \mathrm{~km}$ and the ground level seasonally and regionally dependent. The lower part is mostly liquid drops, and the upper part consists of frozen particles with occasional supercooled droplets. For those data, where modeled total liquid water content did not exceed $0.3 \mathrm{~kg} / \mathrm{m}^{2}$, the absence of rain drops was imposed. For those cloudy data, where the total liquid water content exceeded $0.3 \mathrm{~kg} / \mathrm{m}^{2}$, uniformly distributing point rain rates were added randomly with RR from 0 up to $20 \mathrm{~mm} / \mathrm{h}$ within the rain depth of $0.5-4.5 \mathrm{~km}$ dependently on the humidity and temperature profiles. No ice modeling was carried out. The resulting dataset consisted of about 25000 data with different values of geophysical parameters governing microwave brightness temperature of the atmosphereopen ocean system-atmospheric water vapor content, cloud 
liquid water content, rain rate, sea surface wind speed, sea surface salinity, and sea surface temperature.

\section{Methods}

3.1. Geophysical Model for Brightness Temperature Calculation. The geophysical model relates geophysical parameters to observed brightness temperatures. An accurate specification of the geophysical model is the crucial step in developing geophysical parameter retrieval algorithms. A detailed description of the cloud-free part of the model, including recently developed ocean emission model with an advanced emissivity dependence on sea surface wind speed, is given in [41]. This model consists of the ocean emission model and the atmospheric absorption model, accounting for molecular water vapor and oxygen absorption. The study, carried out in [41], made it possible not only to establish the oceanic and clear-sky constituents of the microwave radiation but also to derive constant calibration additions to transform modeled brightness temperature into measured ones.

Under clear-sky conditions, the atmospheric constituents of the total microwave radiation are the functions of the vertical profiles of air pressure, temperature, and humidity. These functions are evaluated using widely used and intensively validated models, [35] for molecular oxygen and [42] for water vapor absorption. The ocean microwave radiation is governed by the ocean emissivity (depending on the polarization state) which for calm sea conditions is a function of frequency, incidence angle, sea surface temperature, and salinity. Modeling of the wind induced component of the ocean emissivity has undergone significant changes during the last several years [33]. The most important outcome of the findings is that the wind induced emissivity is almost twice larger as compared with the one used previously. Moreover, the sensitivity of the oceanic $T_{B}$ to the wind speed increases rapidly starting from some threshold value, and this is probably associated with the foam property changes. The use of the new wind induced emissivity model allowed developing an AMSR2 SWS retrieval algorithm, highly accurate even under extreme wind conditions [43].

The complex dielectric permittivity of water, used in the model both in the sea surface emissivity and reflectivity formulation and in the emissivity of the cloud droplet fresh water, was parameterized using model [44], since this model is extensively validated and valid for the frequencies up to at least $90 \mathrm{GHz}$ for fresh water in the temperature range of $-20^{\circ} \mathrm{C} \div+40^{\circ} \mathrm{C}$ including supercooled water and for sea water in the temperature range of $-2^{\circ} \mathrm{C} \div+29^{\circ} \mathrm{C}$.

Liquid water content absorption and rain rate attenuation were calculated using [35]. The last was parameterized by Liebe and Layton in [35] using a regression fit over the drop shape and size distributions of Laws and Parsons [45]. This parameterization resulted into simple frequency dependent formulation of the rain attenuation coefficient: $\alpha=0.182 \cdot f \cdot a \cdot \mathrm{RR}^{b}(\mathrm{~dB} / \mathrm{km})$, where $a=2.31 \cdot 10^{-4} \cdot f^{1.42} ; b=$ $0.851 \cdot f^{0.158}$ for $6.9 \mathrm{GHz} ; b=1.41 \cdot f^{-0.0779}$ for $10.65 \mathrm{GHz} ; f$ is frequency in $\mathrm{GHz}$, and $\mathrm{RR}$ is rain rate in $\mathrm{mm} / \mathrm{h}$.

After all the models for the microwave radiation interaction with the atmosphere-ocean system were defined, the brightness temperatures for frequencies, polarization, and angles of incidence of AMSR2 instrument were calculated for the dataset, described in Section 2. Normally distributed radiometric noise with $0.5 \mathrm{~K}$ equivalent temperature was added to the resulting $T_{B}$ values. The whole matched up dataset of geophysical parameters and AMSR2 $T_{B}$ served as a base for the inverse problem solution, for RR retrieval algorithm development.

3.2. Neural Network-Based Inversion. A neural network (NN) was trained to invert the simulated AMSR2 brightness temperatures back to the rain rates. Supposing that $T_{B}$ differences at C- and X-band AMSR2 channel are less dependent on sea surface emission than $T_{B}$ values, we used $4 \mathrm{NN}$ inputs for RR retrievals: $\Delta T_{B}{ }_{7,6}=T_{B 07}{ }^{\mathrm{V}}-T_{B 06}{ }^{\mathrm{V}}, \Delta T_{B}{ }_{10,7}^{\mathrm{V}}=T_{B 10}{ }^{\mathrm{V}}-T_{B 07} \mathrm{~V}$, $\Delta T_{B}{ }_{7,6}{ }_{7,6}=T_{B 07}{ }^{\mathrm{H}}-T_{B 06}{ }^{\mathrm{H}}$, and $\Delta T_{B}{ }_{10,7}{ }^{\mathrm{H}}=T_{B 10}{ }^{\mathrm{H}}-T_{B 07}{ }^{\mathrm{H}}$, where $T_{B 06}{ }^{\mathrm{V}}, T_{B 06}{ }^{\mathrm{H}}, T_{B 07}{ }^{\mathrm{V}}, T_{B 07}{ }^{\mathrm{H}}, T_{B 10}{ }^{\mathrm{V}}$, and $T_{B 10}{ }^{\mathrm{H}}$-AMSR2 brightness temperatures measured at $6.9,7.3$ and $10.65 \mathrm{GHz}$ at vertical and horizontal polarizations correspondingly.

The main advantage of a neural network as an inversion function is that it does not require the a priori knowledge of a transfer function, which is nonlinear and not known in advance. $\mathrm{NN}$ was trained using randomly selected half of the dataset of the simulated brightness temperatures and the corresponding rain rates. Then it was tested using the other half to which $\mathrm{NN}$ algorithm was applied. This was done to avoid overtraining NN, meaning the loss of generalization features.

Standard neural network of multilayer perceptron (MLP) type with feedforward backpropagation of errors was used to connect the simulated brightness temperature differences with the RRs. MLP neural network is a processing block in which input parameters of the task (in our case four $\Delta T_{B}$ ) relate to its output parameter (RR) through the system of neurons at hidden layers [46]. The MLP configuration with a single hidden layer was used since in the tasks of the best approximation any continuous on a finite interval function can be approximated by a neural network of MLP type with one hidden layer. The numerical experiments with other configurations confirmed that including additional layers led to rapid loss of the generalization capabilities, especially for noisy data [47].

Training was carried out via supervised learning and feedforward backpropagation of errors, starting from various random initial weights to avoid getting local minima. The NN configuration was complicated until the testing error started to increase. It was found that a simple $\mathrm{NN}$ configuration consisting of a single hidden layer of 15 neurons ensured the least retrieval error of $1.5 \mathrm{~mm} / \mathrm{h}$ both for training and testing datasets. The scatterplot of retrieved RR values versus in situ ones is presented in Figure 2. By saying "in situ" here we mean not measured but modeled RRs used for the brightness temperature simulation. The greatest error in the rain rate retrievals is observed for low $\mathrm{RR}$ values: for $\mathrm{RR}<2 \mathrm{~mm} / \mathrm{h}$ the root mean square error $\sigma_{\mathrm{RR}}=2.5 \mathrm{~mm} / \mathrm{h}$. The exclusion of clear sky data from consideration leads to the increase in the retrieval accuracy. Thus, when we used accurate estimation of the atmospheric absorption at $10.65 \mathrm{GHz}$ as 


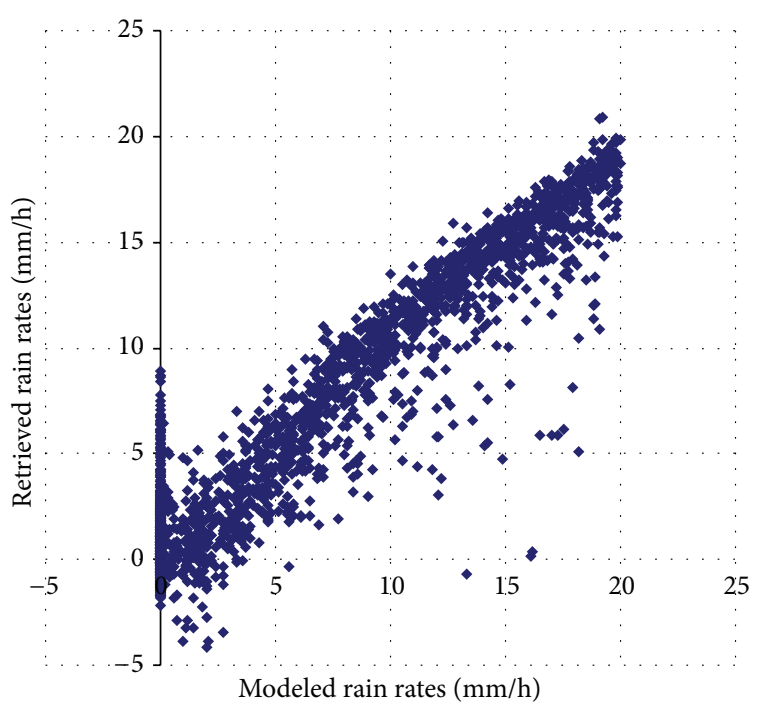

FigURE 2: Scatterplot of retrieved rain rate values versus modeled rain rates for testing dataset.

a criterion to identify the rain pixels, we obtained $\sigma_{\mathrm{RR}}$ of $0.7 \mathrm{~mm} / \mathrm{h}$.

Also it can be seen that the information from 4 brightness temperature differences is not sufficient to properly resolve the similarity between cloud liquid water and rain drop influence upon the brightness temperature. Large scatter of the retrieved rain rates from in situ ones for the whole dataset is inherently caused by the geophysical model and use of low microwave frequencies: all kinds of liquid drops lead to brightness temperature increase. Since ice clouds and ice precipitation in the form of snow, graupel, and hail are not modeled, their presence will lead to additional large rain rate retrieval errors. Nevertheless the use of low frequency measurements for rain rate retrievals is not so much influenced by ice and rain precipitation parameters as the use of higher frequency passive microwave measurements [27].

3.3. Radio Frequency Interference Handling. Before the algorithm validation using AMSR2 measurement data, it was necessary to exclude from the consideration the pixels contaminated by radio frequency interference (RFI). Low level RFI contamination is difficult to be identified over oceans [48]. At the same time for suggested algorithm application it is absolutely imperative since some RFI types manifest themselves identically to precipitation. Figure 3 illustrates two simultaneous RFI in the field of $\Delta T_{B}^{\mathrm{H}}{ }_{10,7}$, the difference in AMSR2 measurements at $10.65 \mathrm{GHz}$ and $7.3 \mathrm{GHz}$, horizontal polarization $(H)$, on 3 September 2012 at $~ 3: 20$ UTC. Areas 1 and 2 indicate the observable increases of $T_{B}$ at $10.65 \mathrm{GHz}$ relative to $T_{B}$ at $7.3 \mathrm{GHz}$. The reasons of these increases are different: area 1 corresponds to rain, whereas area 2 corresponds to the RFI at $10.65 \mathrm{GHz}$ on horizontal polarization. There is one more type of RFI clearly observable in area 3 , RFI at $7.3 \mathrm{GHz}$ on horizontal polarization. The method to discriminate RFI contaminated pixels from rain

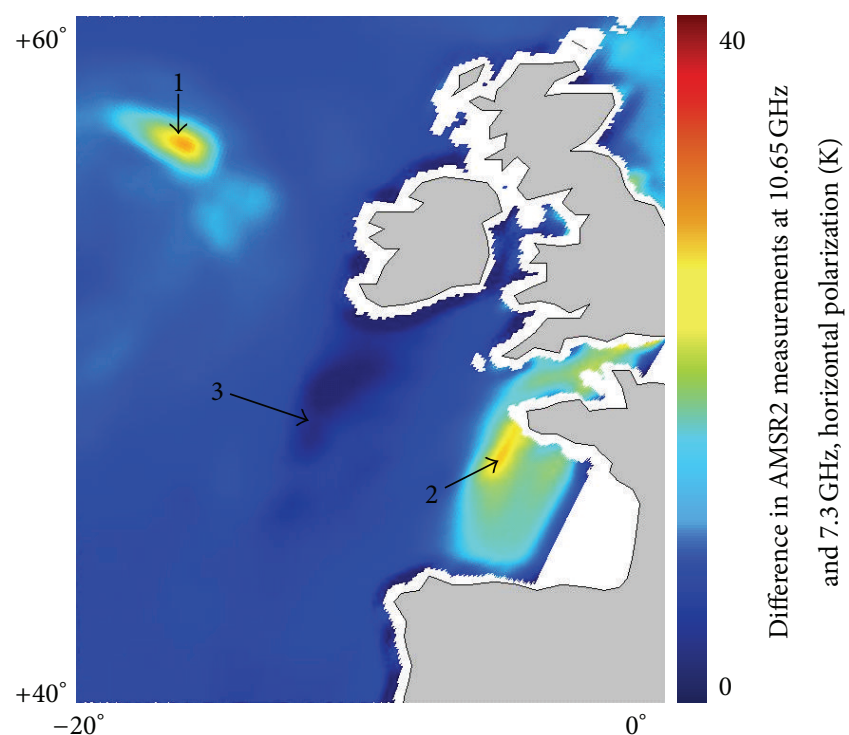

FIGURE 3: Field of $\Delta T_{B}{ }^{\mathrm{H}}$ 10,7 ; difference in AMSR2 measurements at $10.65 \mathrm{GHz}$ and $7.3 \mathrm{GHz}$, horizontal polarization $(\mathrm{H})$, on 3 September 2012 3:20 UTC. 1, area of precipitation, 2, RFI at $10.65 \mathrm{GHz} \mathrm{H}$, and 3, $\mathrm{RFI}$ at $7.3 \mathrm{GHz} \mathrm{H}$.

is based on the analysis of the modeled $T_{B}$ values and their combinations. This analysis allowed suggesting several functions of AMSR2 $T_{B}$ at C- and X-band channels, the threshold values of which could be the indicators of the corresponding RFI. This method is planned to be published and not described here since it goes beyond the scope of this paper. Nevertheless during the validation it was applied to AMSR2 measurement data to remove RFI contaminated pixels from consideration.

\section{Validation Procedure}

The validation of the suggested algorithm was carried out on the base of the comparison of the rain rates retrieved from AMSR2 measurement data with TRMM Level 2 RR product downloaded from the Remote Sensing System (RSS) web site (http://www.remss.com/missions/tmi), based on the measurements of passive microwave instrument TMI. TMI operates on the TRMM satellite in a semiequatorial orbit, measuring microwave radiation in a wide swath of $850 \mathrm{~km}$ and covering a global region from $40 \mathrm{~S}$ to $40 \mathrm{~N}$ at a pixel resolution of $0.25 \mathrm{deg}(\sim 25 \mathrm{~km})$. TMI products are produced by RSS and sponsored by the NASA Earth Science MEaSUREs DISCOVER Project. RSS TMI data are provided as daily gridded data, separated into ascending and descending orbit segments. RSS rain rate products are derived using the algorithm described in [17]. The unique highest quality of all RSS products is ensured by permanent calibration and algorithm upgrading taking into account the newest knowledge and data available. The validation of the last (Version-7) rain rate products is given in [49]. TMI rain rate estimates are also considered to be mostly reliable since TRMM mission was specifically planned for rain measurements. Beside TMI there is also an active microwave instrument, precipitation radar, 


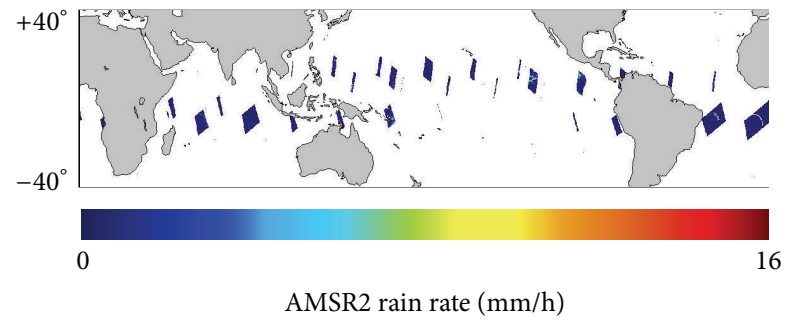

FIgURE 4: AMSR2 rain rates $(\mathrm{mm} / \mathrm{h})$, retrieved with the new algorithm, collocated within 10-minute time difference with RSS TRMM Microwave Imager rain rates. 25 August 2012.

onboard the TRMM. It measures radar backscatter from rain drops during pushbrooming instant measurements with high accuracy and much higher resolution $(\sim 5 \mathrm{~km})$ than that of the radiometer in a narrower swath [7].

Since the TRMM has a nonsun synchronous orbit, TMI data are mostly appropriate for the creation of global collocated in time and space with AMSR2 measurements dataset.

Calibrated Level 1B brightness temperature data from AMSR2 are available starting from August 2012 through GCOM-W1 Data Providing Service (https://gcomw1.jaxa.jp/). The spatial resolution depends on the channel frequency but the pixel size for C- and X-band channel measurements is the same $(\sim 10 \mathrm{~km})$.

For the collocation with the gridded TRMM RR product, AMSR2 Level 1B swath measurement data for 2012-2014 were gridded onto the same grid using Delaunay triangulation and triangle-based linear interpolation [50]. Both ascending and descending orbits were gridded within the geographical region $40 \mathrm{~S} \div 40 \mathrm{~N}$ at a pixel resolution of $0.25 \mathrm{deg}$. After gridding, time collocation was applied to select only those pixels where AMSR2 and TMI measurement times were within 10 minutes. Tight time collocation criterion was set due to fast changing atmospheric state. TMI RR product daily averaging did not present a problem since at higher latitudes orbit segments overlap within local regions and within a short measurement time. AMSR2 orbits do not overlap within 40 S $\div 40 \mathrm{~N}$.

After the collocation the developed algorithm was applied to AMSR2 measurement differences at C- and X-band channels. The last were calculated after the calibration additions had been added to AMSR2 measurement data. These additions had been derived recently as a result of the comparison between simulated brightness temperature values and measured $T_{B} s$ [41]. They can be considered as a bridge between modeled and measured AMSR2 $T_{B}$ s accounting jointly for the geophysical model inconsistencies and the calibration uncertainties. An example of daily coverage of the collocated rain rates is shown in Figure 4. The strips of the collocated pixels move from day to day, during several months filling in the whole zone from $40 \mathrm{~S}$ to $40 \mathrm{~N}$. Five-month coverage for 2012 is shown in Figure 5.

Following the results of the numerical experiment (low performance of AMSR2 RR retrieval algorithm at low rain rates), we did not validate the algorithm for $\mathrm{RR}=0$. For the algorithm validation only those data were selected where RSS

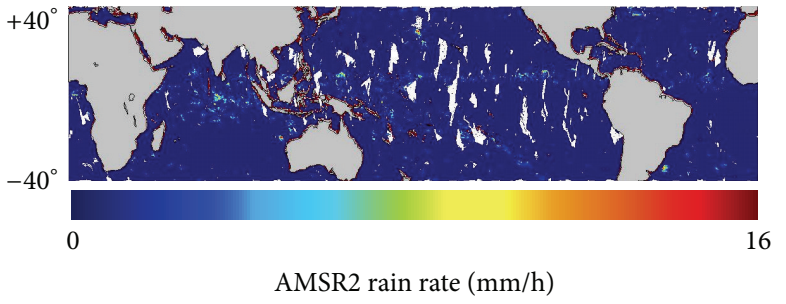

FIGURE 5: A 5-month AMSR2 rain rates $(\mathrm{mm} / \mathrm{h})$, retrieved with the new algorithm, collocated within 10-minute time difference with RSS TRMM Microwave Imager rain rates for 2012.

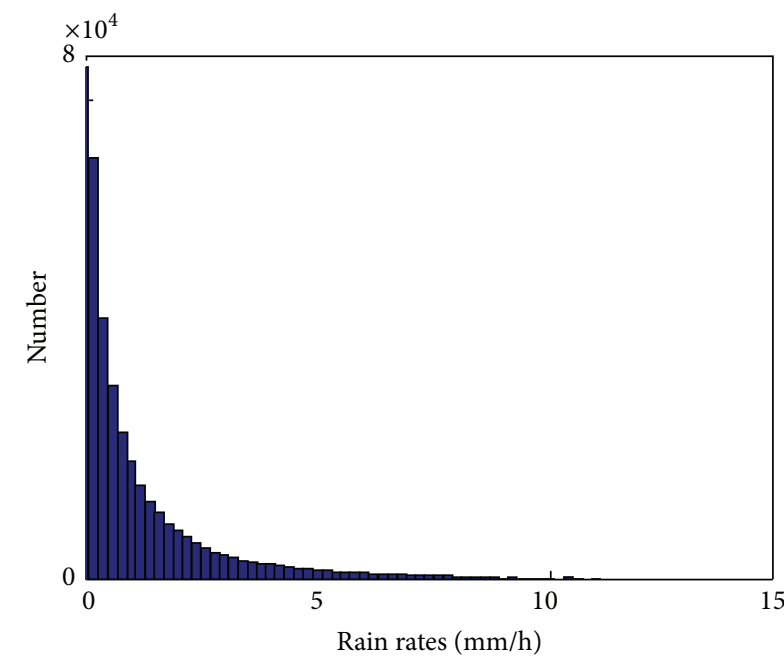

FIGURE 6: Distribution of rain rates in the TMI validation dataset for the time period of August 2012-April 2014.

RR were not equal to zero. The resulting datasets included 90432 data for the 5 months of 2012, 200521 data for the whole year of 2013, and 73214 data for the first 4 months of 2014 . Totally 364167 data with nonzero rain rates comprised the whole validation dataset.

The maximum value of the TMI RR in the validation dataset was $23.5 \mathrm{~mm} / \mathrm{h}$. $93.4 \%$ of all data were less than $5 \mathrm{~mm} / \mathrm{h}$ and only remaining $6.6 \%$ exceeded $5 \mathrm{~mm} / \mathrm{h}$. TMI RR distribution in the validation dataset is presented in Figure 6.

To compare the algorithm performance relative to TMI RR product with another algorithm performance we validated also AMSR2 RSS RR product against the same TMI dataset. It was expected that since all Remote Sensing Systems passive microwave products had been accurately intercalibrated the two different RSS RR products should demonstrate high correlation. At the same time we supposed it was more reasonable to use TMI RR product for the validation since this product is being constantly calibrated with the precipitation radar rain rates which can be considered as in situ RR data.

\section{Results and Discussion}

The results of the comparison of the RRs, retrieved from AMSR2 data, with TMI RRs for the whole RR range are 
presented in the scatter plot in Figure 7. Color in the Figure 7 denotes the number of the data contributing to the scatter plots. The total retrieval error, calculated as a root mean square difference for the whole match-up dataset, is $\sigma=$ $1 \mathrm{~mm} / \mathrm{h}$. The correlation coefficient $\mathrm{Rc}=0.8$; the equation of the linear trend is $y=0.8 x+0.3$.

It can be seen that most of AMSR2 retrievals (94\%) do not scatter from TMI rain rates larger than $\pm 2 \sigma$. Only $6 \%$ of all AMSR2 retrieved rain rates differ from those of TMI by more than $2 \mathrm{~mm} / \mathrm{h}$. These large differences can be due to many reasons. One of the most probable sources of the errors is the difficulty for the algorithm to distinguish between high total cloud liquid water contents and rain rates, following the simplest parameterization of used liquid cloud, rain model and the absence of any ancillary data. Another important reason is not accounting for ice clouds. Some large errors can also be caused by nonzero time difference between TMI and AMSR2 measurements.

The error for the range of rain rates less than $5 \mathrm{~mm} / \mathrm{h}$ is $0.6 \mathrm{~mm} / \mathrm{h}, \mathrm{Rc}=0.6$, and for those rains where $\mathrm{RR}<2(80 \%$ of all data) $\sigma=0.3 \mathrm{~mm} / \mathrm{h}, \mathrm{Rc}=0.4$; so for low rain rates the algorithm performs worse (the relative error is larger) than for the whole RR range. We suppose that an attempt can be undertaken to overcome this inadequacy in the future by means of the combined use of C- and X-band measurements and higher frequency measurements at $22-37 \mathrm{GHz}$ range allowing accurate total cloud liquid water content retrievals under light rains. Such a possibility yet needs to be studied using more advanced forward modeling.

For the rain rates higher than $10 \mathrm{~mm} / \mathrm{h}$ the retrieval error is $2.3 \mathrm{~mm} / \mathrm{h}$. After the exclusion of large error rare cases $(15 \%$ of all data with $\mathrm{RR}>10 \mathrm{~mm} / \mathrm{h}$ with more than $2 \sigma$ deviation), probably associated with fast changing atmospheric state and nonzero time difference in measurements, the retrieval error totaled $1.1 \mathrm{~m} / \mathrm{s}$.

High rain rate retrievals are the subject of special consideration since the complexity of the precipitation modeling under heavy rains definitely cannot be captured by the simple parameterization used in this study. Nonuniform hydrometeor parameter distribution, changing with height and within a footprint, as well as ice clouds and precipitation should be taken into account. Rain rate retrievals in heavy rains, accompanying such extreme events as tropical hurricanes, need to be studied separately since intensive rains modify dramatically both the atmospheric properties and the emissivity of the ocean surface. Under hurricane-force winds the new object appears in the atmosphere close to the ocean surface-the spray layer, generated by breaking waves. This layer of large-scale salt hydrometeors significantly changes the microwave radiation and its polarization state and its influence should be modeled along with rain effect.

Moreover, heavy rains are associated with heavy convection, correlated with large cloud ice particles such as hail. Under conditions of deep convection there may exist large precipitation systems of the spatial scales from 40 to $500 \mathrm{~km}$ or larger. Such mesoscale convective systems are long-lived, cause intense precipitation, and with high probability produce hail [51]. The size of hail and graupel particles in such

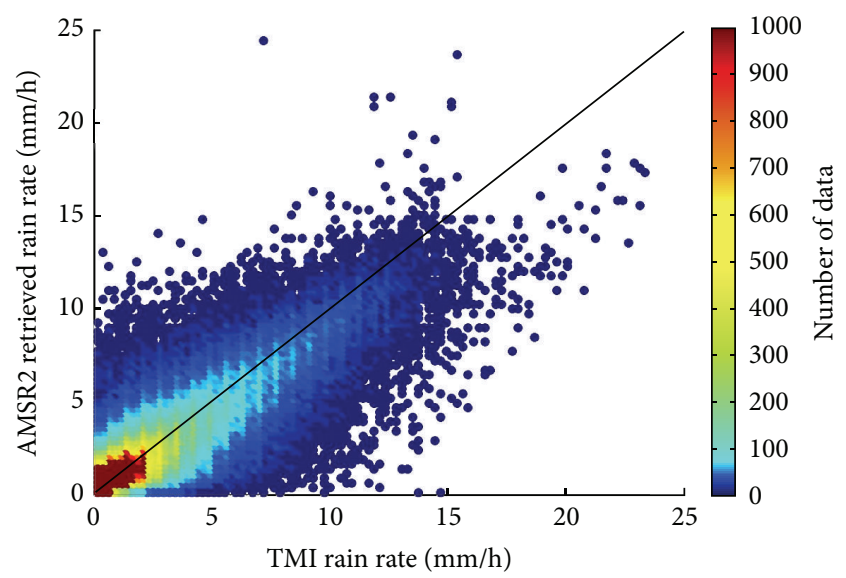

FIGURE 7: Scatter plot of rain rate, retrieved from GCOM-W1 AMSR2 using newly developed algorithm, versus TMI rain rate (Remote Sensing Systems daily product) for the period of August 2012-April 2014. Time collocation is within 10 minutes.

precipitation systems reaches several centimeters [52] which is much more than the wave lengths of low frequency AMSR2 channels. Radiative transfer model in this case cannot be used in its simplified version and its solution requires full Mie multiple scattering computations. In such a case not taking into account ice scattering introduces nonnegligible errors in numerical modeling and following algorithm development.

Analyzing satellite passive microwave rain rate fields we need to have in mind that the highest rain rates occur over the regions with comparatively small areas. Low resolution passive microwave measurements are smoothed; high RR values are averaged with low and zero RRs prevailing over the most part of a pixel. Thus, actual rain rates can be considerably larger than indicated by passive microwave products. This important aspect of spatial smoothing also needs to be considered in any validation studies which use the measurements of different spatial scales.

Figure 8 illustrates this difference in rain rate estimates by TRMM Microwave Imager (TMI RR) and by TRMM Precipitation Radar (PR RR) for the hurricane Danas on 7 October 2013. The maximum TMI RR in the RR field presented in Figure 8 is $15.7 \mathrm{~mm} / \mathrm{h}$, whereas the maximum PR RR for the same field, simultaneously measured in a narrower PR swath, is $184.3 \mathrm{~mm} / \mathrm{h}$. PR data were downloaded from NASA's Goddard Earth Sciences (GES) Data and Information Services Center (DISC). This specific case is a rare case of quasisynchronous imaging of the typhoon (associated with heavy rain) by TMI and AMSR2 instruments. We built RR fields both for TMI RR product and for AMSR2 RR estimated with the algorithm, developed in this study. Figure 9 shows both fields and the difference between them. Since the difference in these satellite measurements is about 1 hour and 20 minutes, the direct pixel-to-pixel comparison is supposed to be impossible. To calculate and build the difference, all AMSR2 data were spatially shifted so that the center of the typhoon, observed by AMSR2, coincided with its center, observed by TMI. This rather inaccurate procedure allowed 


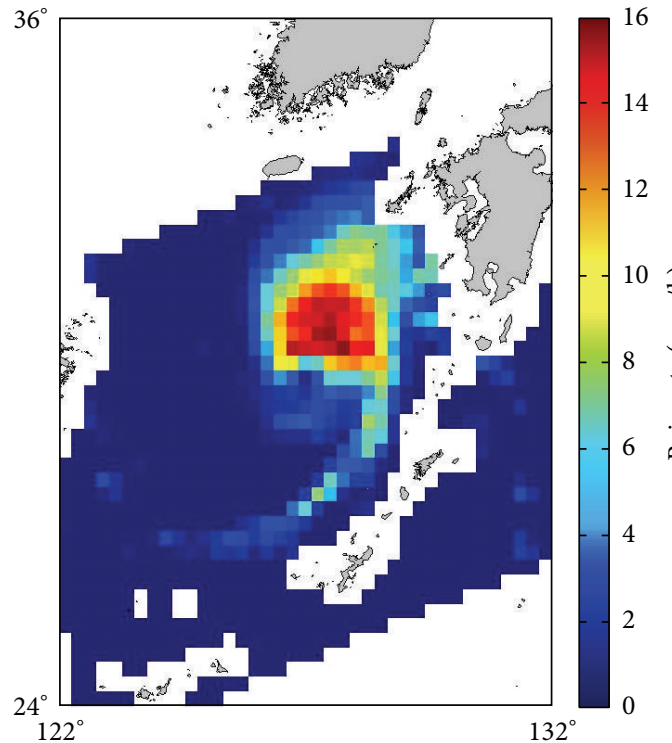

(a)

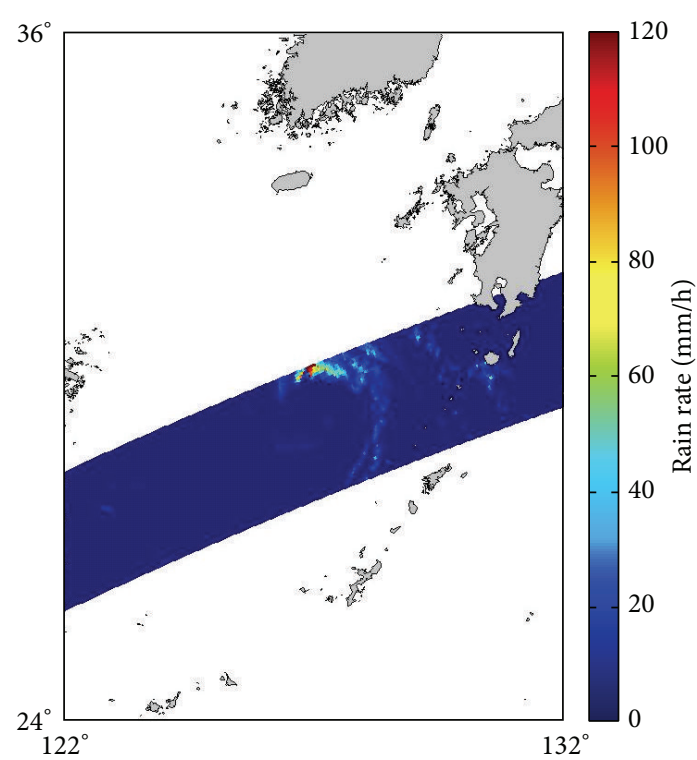

(b)

FIGURE 8: TRMM rain rate fields (mm/h) for the typhoon Danas on 7 October 2013 18:40 UTC: (a) TMI RR product from Remote Sensing Systems and (b) PR RR product from NASA/Goddard Space Flight Center.

nevertheless illustrating the underestimation of rain rates by AMSR2 newly developed algorithm compared with TMI rain rates. Such an underestimation also results from the total validation for high $R R$ values.

To support this validation study we also compared independent AMSR2 rain rate retrievals made by RSS [17] with TMI RR product. Since the fundamentals for TMI and AMSR2 rain rates are the same, we suppose that it makes sense. AMSR2 RSS rain rate product was not used for the algorithm validation since TMI RR product was calibrated against highly accurate precipitation radar measurements, whereas AMSR2 was not. The corresponding scatter plot of RSS AMSR2 RR versus TMI RR is shown in Figure 10(a). In Figure 10(b) the scatter plot of AMSR2 RR, retrieved with the new algorithm, versus TMI RR is shown again to stress the difference.

It can be seen that RSS AMSR2 rain rates are unbiased compared with TMI rain rates. No underestimation of high $\mathrm{RR}$ values is observed. The total retrieval error for the whole dataset is a little bit lower, $0.9 \mathrm{~mm} / \mathrm{h}$ as compared to $1 \mathrm{~mm} / \mathrm{h}$, ensured by the usage of the new algorithm. The correlation coefficient $\mathrm{Rc}=0.8$; the equation of the linear trend is $y=$ $1 x+0.1$. We found that for RSS AMSR2 product the root mean square error for the range of rain rates less than $5 \mathrm{~mm} / \mathrm{h}$ was $0.8 \mathrm{~mm} / \mathrm{h}$, and for the rain rates less than $2 \mathrm{~mm} / \mathrm{h} \sigma$ was $0.6 \mathrm{~mm} / \mathrm{h}, 2$ times higher than with the usage of newly developed AMSR2 algorithm. So, some advantage in the range of low $(<2 \mathrm{~mm} / \mathrm{h})$ rain rates for the new algorithm can be stated compared with the standard AMSR2 RSS RR product. Though for both AMSR2 retrieved RR and RSS RR product the correlation with TMI RR under light rains is far from satisfactory.

\section{Conclusions}

The new algorithm for rain rate (RR) retrievals from the data of Advanced Microwave Sounding Radiometer 2 (AMSR2) onboard GCOM-W1 is developed using 6 low frequency channel measurements at $6.9,7.3$, and $10.65 \mathrm{GHz}$. The algorithm is based on the numerical modeling of brightness temperatures with their following inversion into RR using neural network-based method. The general approximations of forward modeling include a simplified form of the radiative transfer equation, not taking into account ice clouds and precipitation and a simple uniformly distributed rain profile. The validation of the new algorithm is carried out through the comparison of the results of its application to AMSR2 Level $1 \mathrm{~B}$ brightness temperature data with Remote Sensing Systems (RSS) rain rate product, based on Tropical Rain Measurement Mission (TRMM) Microwave Imager (TMI) measurements for the period of August 2012-April 2014. Spatial collocation is ensured by gridding AMSR2 data onto TMI RR grid; time collocation is within 10-minute interval. The root mean square error $\sigma$, calculated for the whole dataset, is about $\sim 1 \mathrm{~mm} / \mathrm{h}$ which is $0.1 \mathrm{~mm} / \mathrm{h}$ greater than $\sigma$ for RSS AMSR2 product. RSS AMSR2 RR product is also validated against the same TMI RR product for the comparison between the performances of RSS and newly developed algorithms.

It is found that the new algorithm outperforms the RSS algorithm for $\mathrm{RR}<2 \mathrm{~mm} / \mathrm{h}$. For this low RR range the error of the new algorithm is $0.3 \mathrm{~mm} / \mathrm{h}$ compared to $0.6 \mathrm{~mm} / \mathrm{h}$ for RSS algorithm. At the same time the new algorithm significantly underestimates rain rates for RR $>10 \mathrm{~mm} / \mathrm{h}$, whereas RSS AMSR2 rain rates are highly correlated and unbiased compared with RSS TMI rain rates for the whole RR range. This significant underestimation is obviously inherent 


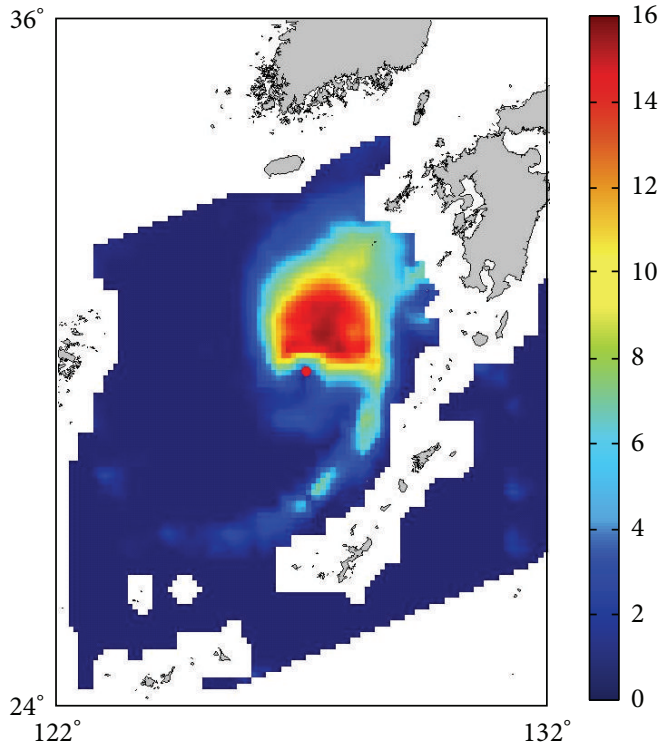

(a)

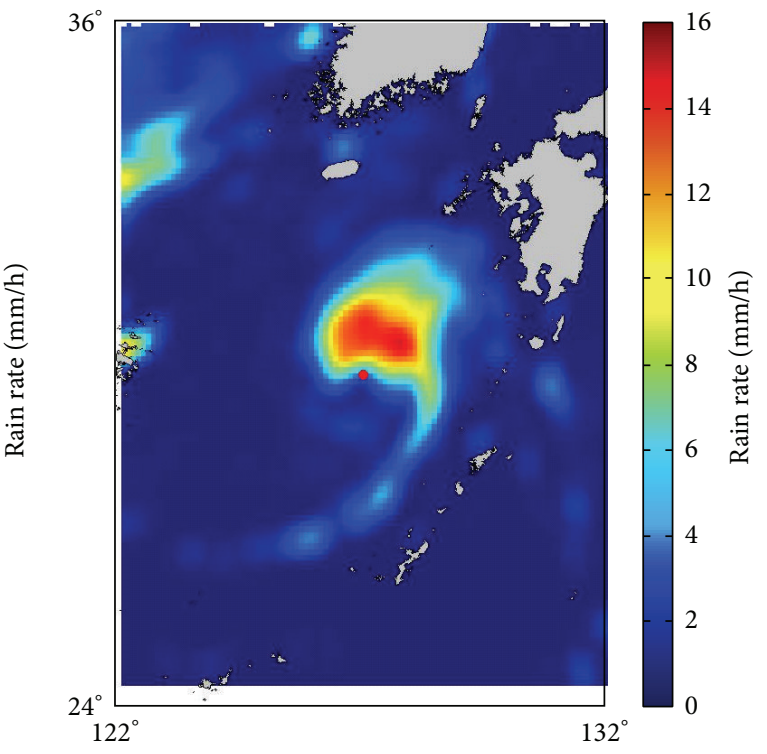

(b)

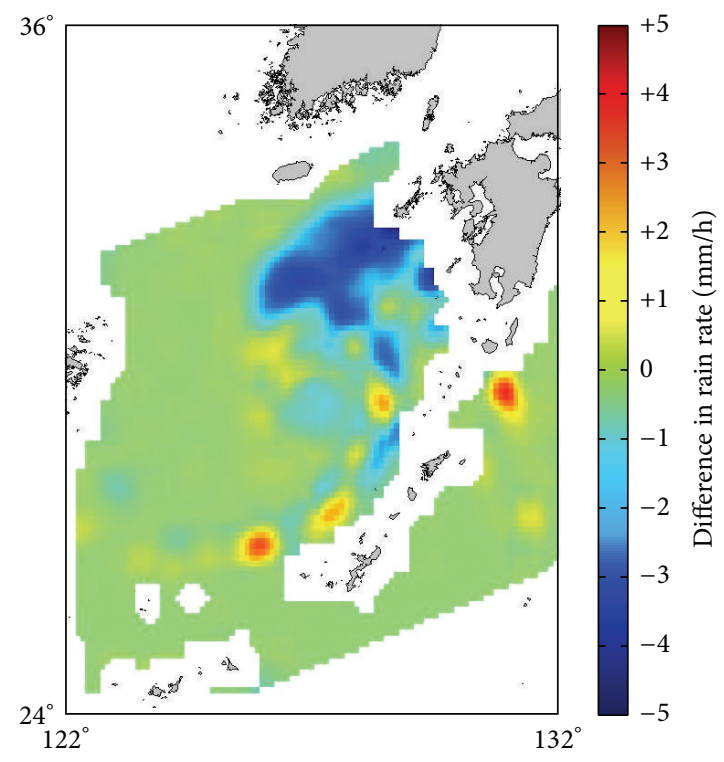

(c)

Figure 9: (a) TMI gridded $(10 \mathrm{~km} \times 10 \mathrm{~km}) \mathrm{RR}$ field $(\mathrm{mm} / \mathrm{h}), 7$ October 2013, $18: 36$ UTC; (b) AMSR2 derived gridded $(10 \mathrm{~km} \times 10 \mathrm{~km}) \mathrm{RR}$ field $(\mathrm{mm} / \mathrm{h}), 7$ October 17:14 UTC, shifted to superpose the typhoon center with that of TMI; (c) $\mathrm{RR}_{\mathrm{AMSR} 2}-\mathrm{RR}_{\mathrm{TMI}}(\mathrm{mm} / \mathrm{h})$.

to the simplified radiation transfer model (RTM), starting to differ from the full RTM at high rain rates, and not accounting for different forms of ice in the atmosphere.

The new algorithm only needs AMSR2 brightness temperature measurement data without any ancillary information and can be used for RR retrievals up to $20 \mathrm{~mm} / \mathrm{h}$, with a retrieval accuracy of $1 \mathrm{~mm} / \mathrm{h}$, degrading for RR higher than $10 \mathrm{~mm} / \mathrm{h}$ to $2.3 \mathrm{~mm} / \mathrm{h}$.

Further work is needed for the algorithm improvement both at very low and high rain rates. This work should include accurate ice modeling and usage of the full RTM. This shall improve the algorithm performance for $\mathrm{RR}>10 \mathrm{~mm} / \mathrm{h}$ and expand the applicability of the algorithm for the estimation of rain rates higher than $20 \mathrm{~mm} / \mathrm{h}$ with reasonable retrieval accuracy.

\section{Conflict of Interests}

The authors declare that they have no conflict of interests regarding the publication of this paper.

\section{Acknowledgments}

Funding for this research was provided by the Mega-Grant of the Russian Federation Government to support scientific research under the supervision of leading scientist at RSHU, 


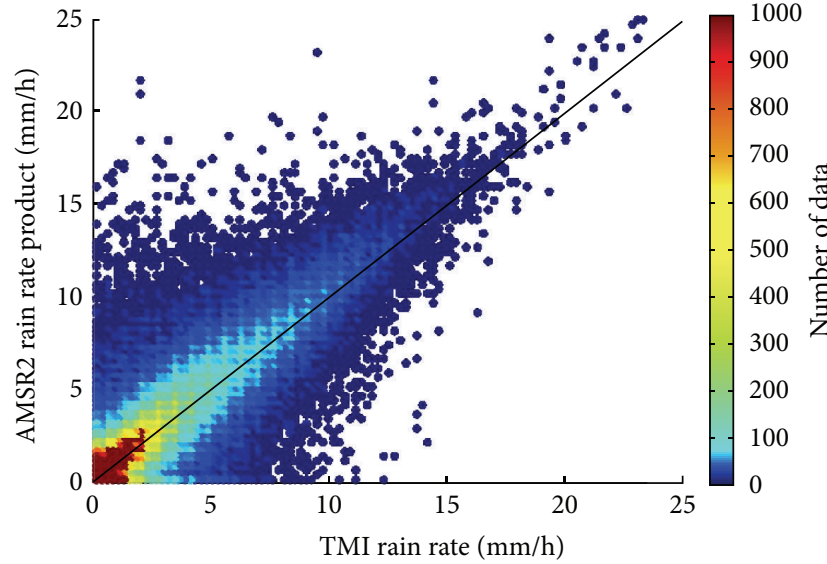

(a)

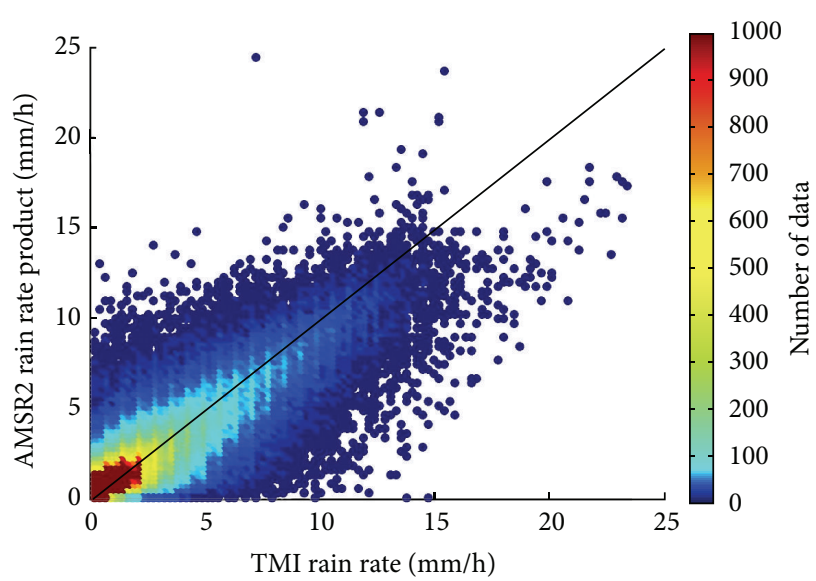

(b)

FIGURE 10: Scatter plot of AMSR2 rain rates versus TMI RSS rain rates for the period of August 2012-April 2014. Time collocation is within 10 minutes: (a) Remote Sensing Systems AMSR2 rain rate product and (b) rain rates, derived from AMSR2 Level 1B brightness temperatures with the new algorithm.

no. 11.G34.31.0078, SMOS+Storm Evolution ESA STSE funding, Russian Foundation for Basic Research Project 14-0591760-AF_a, and Ministry of Education and Science of the Russian Federation Project RFMEFI61014X0006, Agreement no. 14.610.21.0006 "Development of new methods and techniques for monitoring of geophysical and hydrometeorological state of Spitsbergen and Russian West Arctic."

\section{References}

[1] A. Behrangi, M. Lebsock, S. Wong, and B. Lambrigtsen, "On the quantification of oceanic rainfall using spaceborne sensors," Journal of Geophysical Research D: Atmospheres, vol. 117, no. 20, Article ID D20105, 2012.

[2] T. T. Wilheit, "Some comments on passive microwave measurement of rain," Bulletin of the American Meteorological Society, vol. 67, no. 10, pp. 1226-1232, 1986.

[3] G. W. Petty and K. Li, "Improved passive microwave retrievals of rain rate over land and ocean. Part I. Algorithm description," Journal of Atmospheric and Oceanic Technology, vol. 30, no. 11, pp. 2493-2508, 2013.

[4] R. J. Kuligowski, "A self-calibrating real-time GOES rainfall algorithm for short-term rainfall estimates," Journal of Hydrometeorology, vol. 3, no. 2, pp. 112-130, 2002.

[5] G. A. Vicente, R. A. Scofield, and W. P. Menzel, “The operational GOES infrared rainfall estimation technique," Bulletin of the American Meteorological Society, vol. 79, no. 9, pp. 1883-1898, 1998.

[6] A. Behrangi, B. Imam, K. Hsu, S. Sorooshian, T. J. Bellerby, and G. J. Huffman, "REFAME: rain estimation using forwardadjusted advection of microwave estimates," Journal of Hydrometeorology, vol. 11, no. 6, pp. 1305-1321, 2010.

[7] C. Kummerow, W. Barnes, T. Kozu, J. Shiue, and J. Simpson, "The Tropical Rainfall Measuring Mission (TRMM) sensor package," Journal of Atmospheric and Oceanic Technology, vol. 15, no. 3, pp. 809-817, 1998.

[8] G. L. Stephens, D. G. Vane, S. Tanelli et al., "CloudSat mission: performance and early science after the first year of operation,"
Journal of Geophysical Research D: Atmospheres, vol. 114, no. 8, Article ID D00A18, 2009.

[9] G. J. Huffman, R. F. Adler, D. T. Bolvin, and G. Gu, "Improving the global precipitation record: GPCP version 2.1," Geophysical Research Letters, vol. 36, no. 17, p. L17808, 2009.

[10] R. J. Joyce, J. E. Janowiak, P. A. Arkin, and P. Xie, "CMORPH: a method that produces global precipitation estimates from passive microwave and infrared data at high spatial and temporal resolution," Journal of Hydrometeorology, vol. 5, no. 3, pp. 487503, 2004.

[11] R. J. Joyce and P. Xie, "Kalman filter-based CMORPH," Journal of Hydrometeorology, vol. 12, no. 6, pp. 1547-1563, 2011.

[12] A. Behrangi, G. Stephens, R. F. Adler, G. J. Huffman, B. Lambrigtsen, and M. Lebsock, "An update on the oceanic precipitation rate and its zonal distribution in light of advanced observations from space," Journal of Climate, vol. 27, no. 11, pp. 3957-3965, 2014.

[13] A. AghaKouchak, A. Mehran, H. Norouzi, and A. Behrangi, "Systematic and random error components in satellite precipitation data sets," Geophysical Research Letters, vol. 39, no. 9, Article ID L09406, 2012.

[14] A. Y. Hou, R. K. Kakar, S. Neeck et al., "The global precipitation measurement (GPM) mission," Bulletin of the American Meteorological Society, vol. 95, no. 5, pp. 711-722, 2014.

[15] T. T. Wilheit, A. T. C. Chang, M. S. V. Rao, E. B. Rogers, and J. S. Theon, "A satellite technique for quantitatively mapping rainfall rates over the oceans," Journal of Applied Meteorology, vol. 16, no. 5, pp. 551-560, 1977.

[16] M. R. P. Sapiano, T. M. Smith, and P. A. Arkin, "A new merged analysis of precipitation utilizing satellite and reanalysis data," Journal of Geophysical Research D: Atmospheres, vol. 113, no. 22, Article ID D22103, 2008.

[17] K. A. Hilburn and F. J. Wentz, "Intercalibrated passive microwave rain products from the unified microwave ocean retrieval algorithm (UMORA)," Journal of Applied Meteorology and Climatology, vol. 47, no. 3, pp. 778-794, 2008.

[18] F. J. Turk, Z. S. Haddad, and Y. You, "Principal components of multifrequency microwave land surface emissivities. Part I. 
Estimation under clear and precipitating conditions," Journal of Hydrometeorology, vol. 15, no. 1, pp. 3-19, 2014.

[19] T. Wilheit, R. Adler, S. Avery et al., "Algorithms for the retrieval of rainfall from passive microwave measurements," Remote Sensing Reviews, vol. 11, no. 1-4, pp. 163-194, 1994.

[20] T. Wilheit, C. D. Kummerow, and R. Ferraro, "NASDARainfall algorithms for AMSR-E," IEEE Transactions on Geoscience and Remote Sensing, vol. 41, no. 2, pp. 204-214, 2003.

[21] G. W. Petty, "Physical retrievals of over-ocean rain rate from multichannel microwave imagery. Part I: theoretical characteristics of normalized polarization and scattering indices," Meteorology and Atmospheric Physics, vol. 54, no. 1-4, pp. 7999, 1994.

[22] C. Kummerow, R. A. Mack, and I. M. Hakkarinen, "A selfconsistency approach to improve microwave rainfall rate estimation from space," Journal of Applied Meteorology, vol. 28, no. 9, pp. 869-884, 1989.

[23] C. Kummerow and L. Giglio, "A passive microwave technique for estimating rainfall and vertical structure information from space. Part I: algorithm description," Journal of Applied Meteorology, vol. 33, no. 1, pp. 3-18, 1994.

[24] F. J. Wentz and R. W. Spencer, "SSM/I rain retrievals within a unified all-weather ocean algorithm," Journal of the Atmospheric Sciences, vol. 55, no. 9, pp. 1613-1627, 1998.

[25] R. R. Ferraro, "Special sensor microwave imager derived global rainfall estimates for climatological applications," Journal of Geophysical Research D: Atmospheres, vol. 102, no. 14, pp. 1671516735, 1997.

[26] F. J. Wentz, L. Ricciardulli, K. Hilburn, and C. Mears, "How much more rain will global warming bring?" Science, vol. 317, no. 5835, pp. 233-235, 2007.

[27] P. Bauer and P. Schluessel, "Rainfall, total water, ice water, and water vapor over sea from polarized microwave simulations and special sensor nicrowave/imager data," Journal of Geophysical Research, vol. 98, no. D11, pp. 20-759, 1993.

[28] C. Kummerow, W. S. Oison, and L. Giglio, "A simplified scheme for obtaining precipitation and vertical hydrometeor profiles from passive microwave sensors," IEEE Transactions on Geoscience and Remote Sensing, vol. 34, no. 5, pp. 1213-1232, 1996.

[29] B. Lin and W. B. Rossow, "Precipitation water path and rainfall rate estimates over oceans using special sensor microwave imager and international satellite cloud climatology project data," Journal of Geophysical Research D: Atmospheres, vol. 102, no. 8, pp. 9359-9374, 1997.

[30] S. Chandrasekhar, Radiative Transfer, Dover Publications, New York, NY, USA, 1960.

[31] C. Kummerow and R. Ferraro, "Algorithm theoretical basis document: EOS/AMSR-E level-2 rainfall," Colorado State University Report, Colorado State University, Fort Collins, Colo, USA, 2007.

[32] C. Kummerow, Y. Hong, W. S. Olson et al., "The evolution of the Goddard profiling algorithm (GPROF) for rainfall estimation from passive microwave sensors," Journal of Applied Meteorology, vol. 40, no. 11, pp. 1801-1820, 2001.

[33] T. Meissner and F. J. Wentz, "The emissivity of the ocean surface between 6 and 90 GHzover a large range of wind speeds and earth incidence angles," IEEE Transactions on Geoscience and Remote Sensing, vol. 50, no. 8, pp. 3004-3026, 2012.

[34] K. Imaoka, M. Kachi, M. Kasahara, N. Ito, K. Nakagawa, and T. Oki, "Instrument performance and calibration of AMSR-E and
AMSR2," International Archives of the Photogrammetry, Remote Sensing and Spatial Information Science, vol. 38, no. 8, pp. 13-18, 2010.

[35] H. J. Liebe and D. H. Layton, "Millimeter-wave properties of the atmosphere: Laboratory studies and propagation modeling," NTIA Report 87-24, National Technical Information Service, Boulder, Colo, USA, 1987.

[36] S. Y. Matrosov and E. M. Shulgina, "Scattering and attenuation of microwave radiation by precipitation," Main Geophysical Observatory Transactions, vol. 448, pp. 85-94, 1982.

[37] J. Vivekanandan, J. Turk, and V. N. Bringi, "Ice water path estimation and characterization using passive microwave radiometry," Journal of Applied Meteorology, vol. 30, no. 10, pp. 14071421, 1991.

[38] D. L. Wu, J. H. Jiang, and C. P. Davis, "EOS MLS cloud ice measurements and cloudy-sky radiative transfer model," IEEE Transactions on Geoscience and Remote Sensing, vol. 44, no. 5, pp. 1156-1165, 2006.

[39] L. P. Bobylev, E. V. Zabolotskikh, L. M. Mitnik, and M. L. Mitnik, "Atmospheric water vapor and cloud liquid water retrieval over the arctic ocean using satellite passive microwave sensing," IEEE Transactions on Geoscience and Remote Sensing, vol. 48, no. 1, pp. 283-294, 2010.

[40] I. P. Mazin and A. K. Khrgian, Clouds and Cloudy Atmosphere, Gidrometeoizdat, Leningrad, Russia, 1989.

[41] E. Zabolotskikh, L. Mitnik, and B. Chapron, "An updated geophysical model for AMSR-E and SSMIS brightness temperature simulations over oceans," Remote Sensing, vol. 6, no. 3, pp. 23172342, 2014.

[42] D. D. Turner, M. P. Cadeddu, U. Lohnert, S. Crewell, and A. M. Vogelmann, "Modifications to the water vapor continuum in the microwave suggested by ground-based $150-\mathrm{GHz}$ observations," IEEE Transactions on Geoscience and Remote Sensing, vol. 47, no. 10, pp. 3326-3337, 2009.

[43] E. Zabolotskikh, L. Mitnik, and B. Chapron, "GCOM-W1 AMSR2 and MetOp-A ASCAT wind speeds for the extratropical cyclones over the North Atlantic," Remote Sensing of Environment, vol. 147, pp. 89-98, 2014.

[44] T. Meissner and F. J. Wentz, "The complex dielectric constant of pure and sea water from microwave satellite observations," IEEE Transactions on Geoscience and Remote Sensing, vol. 42, no. 9, pp. 1836-1849, 2004.

[45] J. O. Laws and D. A. Parsons, "The relation of raindrop-size to intensity," Eos, Transactions American Geophysical Union, vol. 24, no. 2, pp. 452-460, 1943.

[46] P. M. Atkinson and A. R. L. Tatnall, "Introduction neural networks in remote sensing," International Journal of Remote Sensing, vol. 18, no. 4, pp. 699-709, 1997.

[47] K. Hornik, "Approximation capabilities of multilayer feedforward networks," Neural Networks, vol. 4, no. 2, pp. 251-257, 1991.

[48] M. Aksoy and J. T. Johnson, "A comparative analysis of low-level radio frequency interference in SMOS and aquarius microwave radiometer measurements," IEEE Transactions on Geoscience and Remote Sensing, vol. 51, no. 10, pp. 4983-4992, 2013.

[49] K. Hilburn, D. Smith, and T. Meissner, "Assessment of remote sensing systems version-7 rain rates," in Proceedings of the EGU General Assembly Conference Abstracts, vol. 15, p. 6120, 2013.

[50] C. B. Barber, D. P. Dobkin, and H. Huhdanpaa, "The quickhull algorithm for convex hulls," ACM Transactions on Mathematical Software, vol. 22, no. 4, pp. 469-483, 1996. 
[51] J. L. Sánchez, M. V. Fernández, J. T. Fernández, E. Tuduri, and C. Ramis, "Analysis of mesoscale convective systems with hail precipitation," Atmospheric Research, vol. 67-68, pp. 573-588, 2003.

[52] A. H. Auer, "Distribution of graupel and hail with size," Monthly Weather Review, vol. 100, no. 5, pp. 325-328, 1972. 

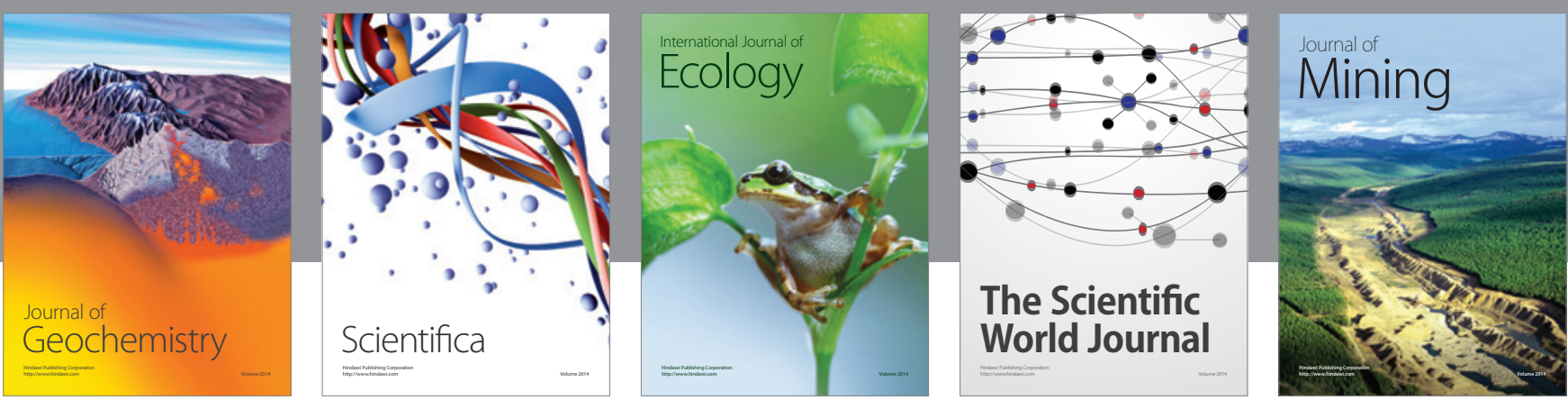

The Scientific World Journal
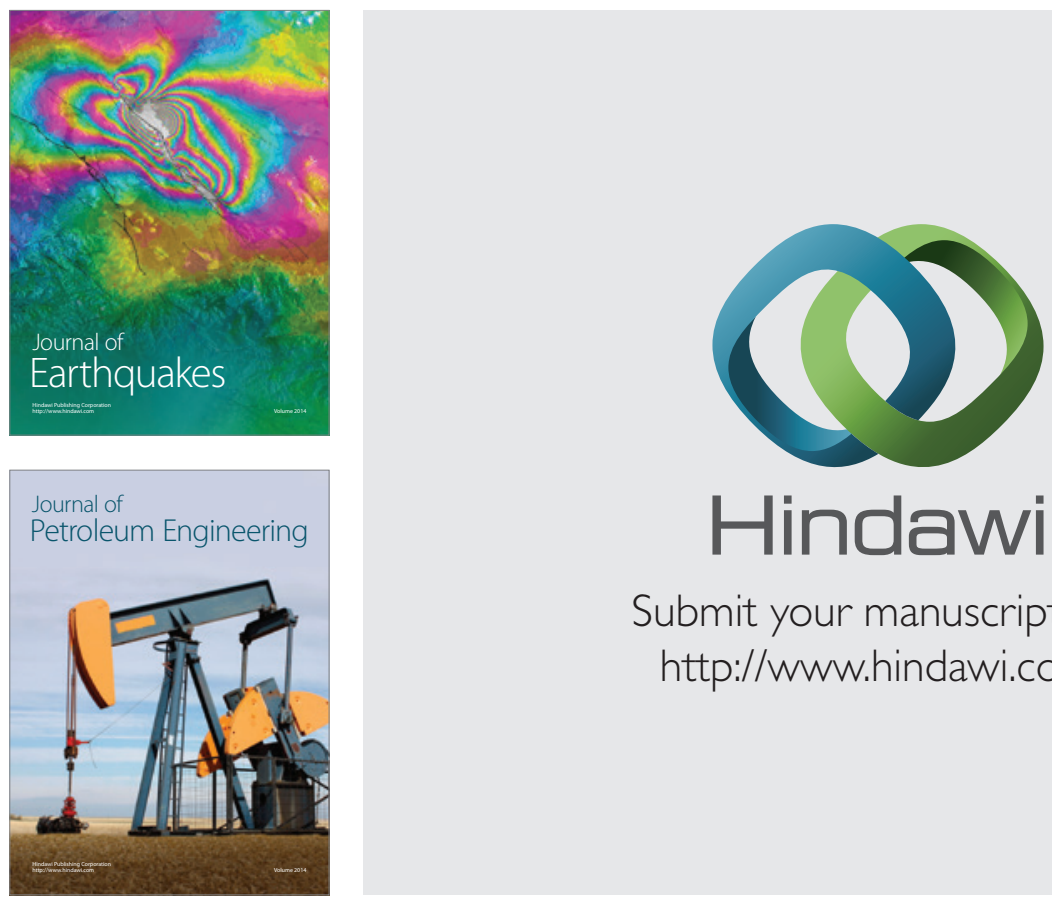

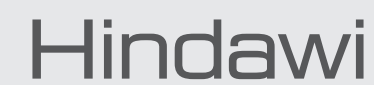

Submit your manuscripts at

http://www.hindawi.com
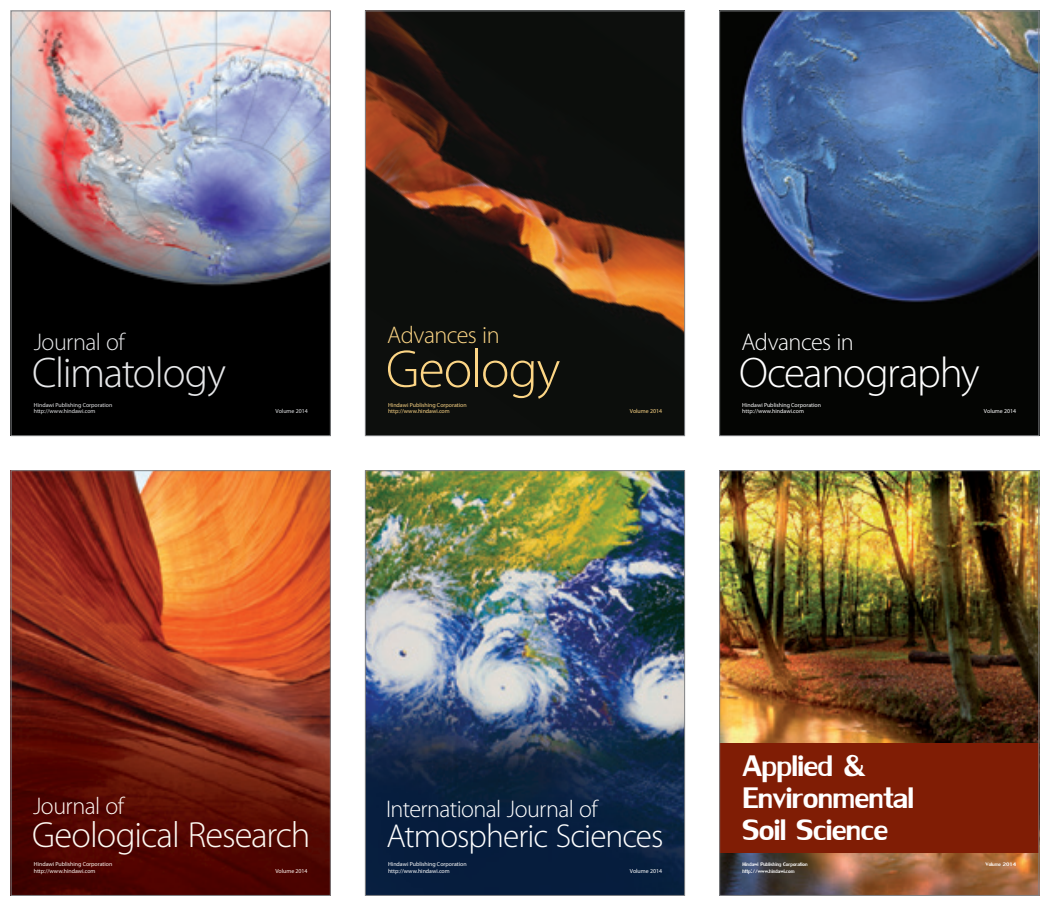
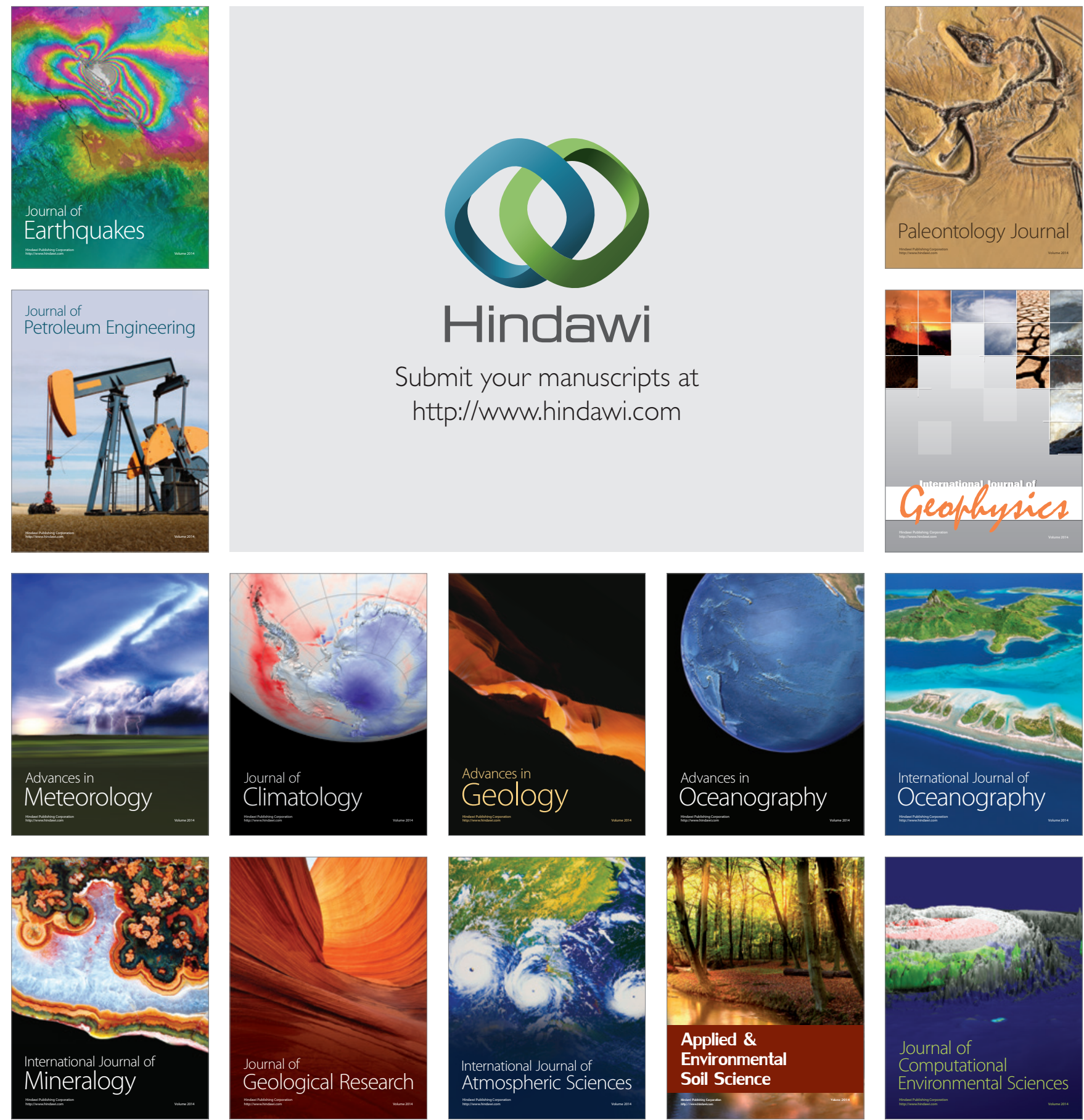